AGH DRILLING, OIL, GAS • Vol. 33 • No. $2 \cdot 2016$

http://dx.doi.org/10.7494/drill.2016.33.2.515

\author{
Tomasz Blacharski*, Piotr Janusz**, \\ Maciej Kaliski**, Łukasz Zabrzeski ${ }^{* * *}$
}

\title{
THE EFFECT OF HYDROGEN TRANSPORTED THROUGH GAS PIPELINES ON THE PERFORMANCE OF NATURAL GAS GRID****
}

\section{INTRODUCTION}

In the energy balance of Poland natural gas covers approximately $13 \%$ of demand for primary energy; however, taking account of the importance of this raw material for the national economy, it should be noted that it plays a crucial role in its development. For several years, a scheme has been implemented for the extension of the national gas grid, intended to improve access for potential customers to the gas infrastructure but also to increase the potential for natural gas supply from new delivery destinations. As of the end of 2015, the natural gas transmission network accounted for $10,966 \mathrm{~km}$. It must not be forgotten that more than $42 \%$ of transmission gas pipelines have been operated for a minimum of 26 years, approximately $33 \%$ have been operated for more than five years, and only $25 \%$ have been put into operation in the last five years. While implementing the scheme for transmission network expansion, every effort has been made to increase its transportation capacity and, hence, its economic viability. In recent years, as a result of the implementation of EU legislation, settlements regarding the volume of natural gas transported have been compiled expressed in units of energy and not in units of volume, as it used to be the practice over the past decades. For the last four years, the volume of natural gas transported through transmission system (including UGS)

* Polska Spółka Gazownictwa Sp. z o.o.

** AGH University of Science and Technology, Faculty of Drilling, Oil and Gas, Krakow, Poland

*** AGH University of Science and Technology, Faculty of Drilling, Oil and Gas, Krakow, Poland, doctoral student

**** This work has been prepared within the statutory research of Faculty of Drilling, Oil and Gas, AGH UST, No. 11.11.190.555 
has been the following: 16.3 billion cubic metres in 2012, 17 billion cubic metres in 2013, 16.5 billion cubic metres in 2014 and 16.2 billion cubic metres in 2015. In units of energy it accounts for $181 \mathrm{TWh}$; 187,3 TWh; $189 \mathrm{TWh}$; 180,9 TWh [5].

High growth in the use of renewable energies should also be noted. This refers primarily to electricity generated from wind and photovoltaic farms. Such energy sourcing is characterised by irregularity and difficulty in storing the energy while it is being generated. Due to this, work has resumed on commercialisation of technologies allowing the storage of excess electricity produced from renewable sources.

One of the possibilities mentioned above is to convert electricity into another energy carrier - hydrogen, for instance, which can be stored over long periods without any loss, and developed in a number of economic areas. Among alternatives for developing a fuel of this kind is its transportation as a mixture with natural gas by using the existing gas network. Account must be taken, though, of the fact that the operating gas grid has been designed and built according to natural gas parameters only. Therefore, while investigating the feasibility of transporting hydrogen and natural gas blend, the effect of this gas on the functioning of the gas pipeline network is a necessary consideration.

The currently operating natural gas transmission system in Poland is characterised by maximum operating pressures not exceeding $8.4 \mathrm{MPa}$. The conducted analyses have assumed that while showing the implications of blending hydrogen with natural gas on its transmission and quality parameters, only pressures up to $10 \mathrm{MPa}$ will be used for analysis purposes. The computations were performed for the following values: normal pressure - $101.325 \mathrm{kPa}, 1 \mathrm{MPa}, 2 \mathrm{MPa}, 4 \mathrm{MPa}, 6 \mathrm{MPa}, 8 \mathrm{MPa}$ and $10 \mathrm{MPa}$. The quality parameters taken into account are lower heating value, higher heating value, the Wobbe index, and the amount of energy per $1 \mathrm{~m}^{3}$ of gas under normal conditions. The transmission parameters (affecting technical and technological aspects of transmission and distribution) are in turn: density, viscosity, real gas deviation factor (pseudo-compressibility factor, $Z$ ) and explosive limits. The likely pressure drop in the gas pipeline at a specified distance using the Panhandle B equation for the flow of natural gas through pipelines has also been analysed. The starting composition of the natural gas without hydrogen blend content to be analysed was the mix of $96 \%$ methane, $1 \%$ ethane and $3 \%$ nitrogen. This composition undergoes changes in proportion to the percentage of hydrogen being added. This change may be expressed as the equation:

$$
x_{n \_n e w}=x_{n \_i}\left(1-x_{H_{2}}\right)
$$

where:

$$
\begin{aligned}
x_{n \_n e w}- & \text { molar fraction of } n^{\text {th }} \text { constituent within the blend with specified per- } \\
& \text { centage of hydrogen; } \\
x_{H_{2}}- & \text { percentage of hydrogen within the blend; } \\
x_{n_{-} i}- & \text { output (starting) value of the percentage of the } n^{\text {th }} \text { constituent. }
\end{aligned}
$$


The percentage of hydrogen added in the mixture and considered in comparative analyses ranges from $0 \%$ to $30 \%$ of molar fraction with the step of 5 percent.

\section{TRANSMISSION PARAMETERS}

One of the main parameters having a material effect on the behaviour of natural gas being transported is the pseudo-compressibility factor $(Z)$ and hence, it was the point of departure for every analysis. As mentioned before, the analyses focused on blends ranging from $0 \%$ to $30 \%$ hydrogen and pressures up to $10 \mathrm{MPa}$; however, in the case of this factor, it was decided to show its values for broader ranges, given the nature of changes occurring when greater ranges are considered in calculations.

Figure 1 shows variations of the $Z$ factor through a pressure range up to $10 \mathrm{MPa}$ and hydrogen blend up to $30 \%$. Figure 2 demonstrates variations in this parameter for pressures up to $30 \mathrm{MPa}$ and hydrogen blend up to $100 \%$. It should be noted that with the increasing molar percentage of hydrogen in the mixture, the value of the pseudocompressibility $Z$ factor increases. To calculate the factor, the Peng-Robinson Equation and the Newton-Raphson method have been applied in iteration steps. Hydrogen has a very low Pitzer acentric factor -0.215 (for comparison, the Pitzer acentric factor for methane is 0.0115 and for ethane 0.105$)$, and also a modest critical pressure (2.016 $\mathrm{MPa}$ while for methane it is $16.04 \mathrm{MPa}$ and for ethane $30.07 \mathrm{MPa}$ ), and a critical temperature (33.10 K while for methane it is $190.55 \mathrm{~K}$ and for ethane $305.5 \mathrm{~K}$ ). All together with a relatively small molar mass of hydrogen, these values allow the $Z$ factor for hydrogen to increase as the pressure increases, unlike natural gas (first a drop is observed, then it starts increasing with the pressure of approximately $17 \mathrm{MPa}$ only).

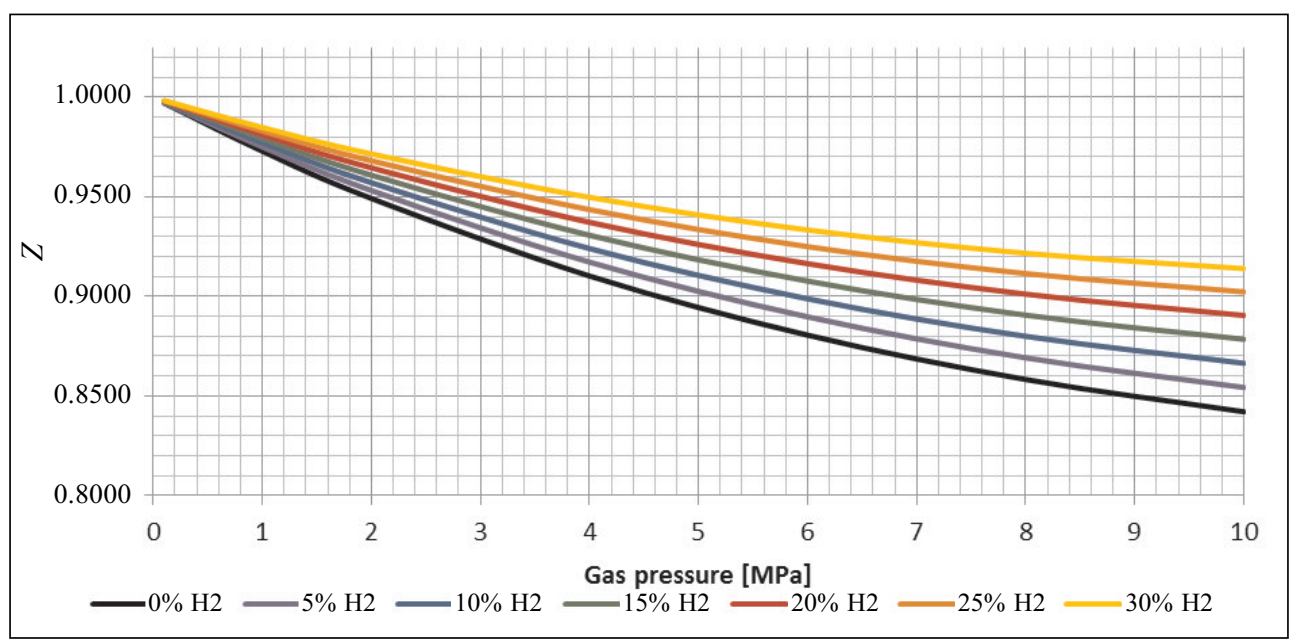

Fig. 1. Variation of pseudo-compressibility $Z$ factor $v s$. pressure and hydrogen percentage 


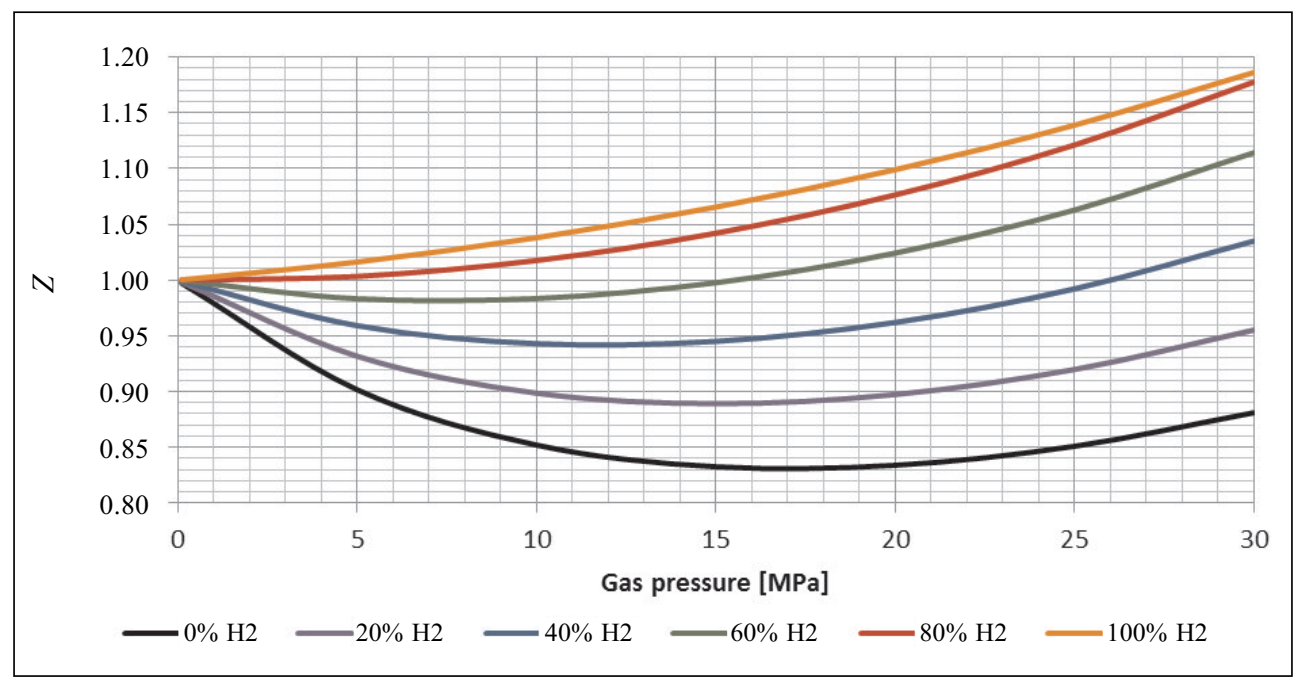

Fig. 2. Variation of pseudo-compressibility $Z$ factor $v s$. pressure and hydrogen percentage

Hydrogen is a very light gas and due to this reason its impact on the density of the whole blend has been examined. The mixture values, depending on the pressure, were calculated by means of Clapeyron equation, taking account of the $Z$ factor obtained for respective values of the pressure and molar percentage of hydrogen in the whole blend. The results have been displayed in Figure 3.

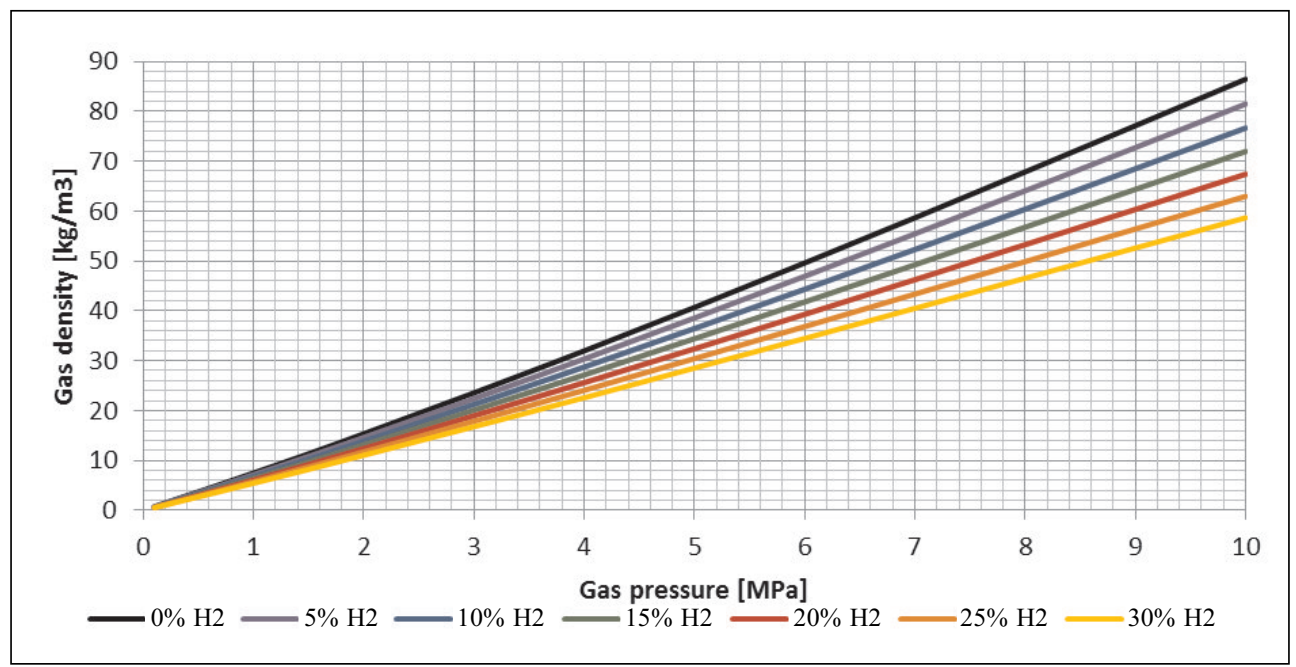

Fig. 3. Gas density variation $\left[\mathrm{kg} / \mathrm{m}^{3}\right]$ vs. gas pressure and hydrogen percentage in the blend 
Variations in gas viscosity were examined using the Lee-Gonzalez correlation. Here, however, the impact was relatively low, the greatest deviations were expected to be seen for highest pressures, in accordance with the principles of thermodynamics. Under this assumption, at $10 \mathrm{MPa}$ pressure and with $30 \%$ hydrogen, the dynamic viscosity value appeared to be $2.4 \%$ lower than in natural gas without hydrogen blend content, under the same pressure and temperature conditions. The difference can be barely seen for pressures lower than $4 \mathrm{MPa}$ (lower than $0.4 \%$ ). The implementation of these changes along with hydrogen physical characteristics into the question of gas transportation over a specified distance has been discussed at a further stage.

Hydrogen is a gas characterised by high explosive range. Its lower explosive limit (LEL) is $4 \%$, and its upper explosive limit (UEL) is as high as $76 \%$. The explosive limit is an air-borne concentration of a vapour, gas or dust that will explode if an ignition source is introduced. The LEL is a concentration of mixture where there is already a potential for an explosion, and the UEL is a concentration of mixture where there is still a potential for an explosion. Blending hydrogen with natural gas will therefore have a significant impact on improving the safety of pure hydrogen use. It is nevertheless supposed that the LEL for natural gas is $5 \%$, and the UEL is $15 \%$. The effect of hydrogen blend content on their values was computed through equations $[1,13]$ :

$$
\begin{gathered}
\mathrm{LEL}=\frac{x_{1}+x_{2}+x_{3}}{\frac{x_{1}}{\mathrm{LEL}_{1}}+\frac{x_{2}}{\mathrm{LEL}_{2}}+\frac{x_{3}}{\mathrm{LEL}_{3}}} \\
\mathrm{UEL}=\frac{x_{1}+x_{2}+x_{3}}{\frac{x_{1}}{\mathrm{UEL}_{1}}+\frac{x_{2}}{\mathrm{UEL}_{2}}+\frac{x_{3}}{\mathrm{UEL}_{3}}}
\end{gathered}
$$

where:

$x_{n}-$ molar fraction of $n^{\text {th }}$ constituent,

$\mathrm{LEL}_{n}$ - lower explosive limit for $n^{\text {th }}$ constituent,

$\mathrm{UEL}_{n}$ - upper explosive limit for $n^{\text {th }}$ constituent.

The results can be seen in Figure 4. In this context, a mention should also be made of the significance of minimum ignition energy in terms of safety concerns. The explosive mixture of pure hydrogen ignites with the energy as low as $0.01 \mathrm{~mJ}$, which represents a value $28 \%$ less than the minimum ignition energy for methane $(0.28 \mathrm{~mJ})$. Ignition sources for a mixture with a minimum ignition energy greater than $0.025 \mathrm{~mJ}$ may be, for instance, electrical discharges such as spark or brush discharges, lightening, and below this value even corona discharges [6]. Blending natural gas with hydrogen will thus reduce transmission safety of this fuel; on the other hand, though, it may appear to be a recipe for the possible transmission of the explosive hydrogen and its broader use [2]. 


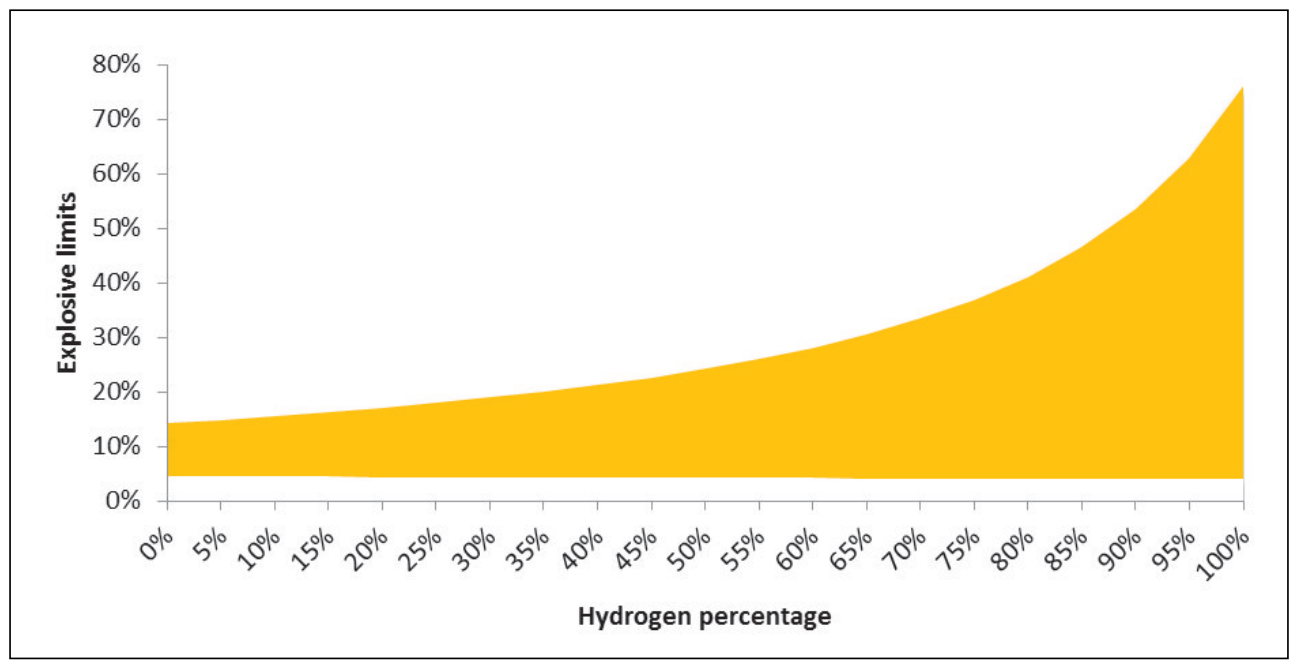

Fig. 4. Explosive limits for natural gas/hydrogen blend vs. hydrogen percentage

\section{QUALITY PARAMETERS OF NATURAL GAS}

Among the analysed quality parameters of the mixture of natural gas and hydrogen are lower heating value, higher heating value, the Wobbe index and the amount of energy per $1 \mathrm{~m}^{3}$ of gas under both actual and transmission conditions. The decision to investigate these parameters only was due to the requirement to make transmission settlements in units of energy. Moreover, the regulations put rigid limits on the values investigated, and if exceeded, the transport of gas by pipelines is prevented.

Given the fact that quality parameters of gaseous fuels are expressed per normal cubic metre, this was done accordingly while presenting the results of the work already carried out. It was decided to reflect them for ranges from $0 \%$ to $100 \%$ hydrogen and $0 \%$ to $30 \%$ with reference to the gas transmitted at $10 \mathrm{MPa}$ pressure.

Figure 5 demonstrates how the value of the molar fraction of hydrogen blended with natural gas affects its higher heating value, lower heating value, and the upper and lower Wobbe index. Since hydrogen has much lower heating values than any other natural gas constituent per cubic metre, its percentage increase in the total volume contributes to reduce the total value of a given quality parameter. Table 1 shows the loss in energy resulting from blending a given amount of hydrogen with natural gas. It is worth noting the fact that with more than $79 \%$ hydrogen, the upper Wobbe index of the whole blend starts again to increase, reaching for the $100 \%$ hydrogen the $93.93 \%$ value of the upper Wobbe index for natural gas without hydrogen blend content. It results from the equation which defines the Wobbe index where the dominator is the square root of the relative density. The same situation occurs in the case of lower Wobbe index. 


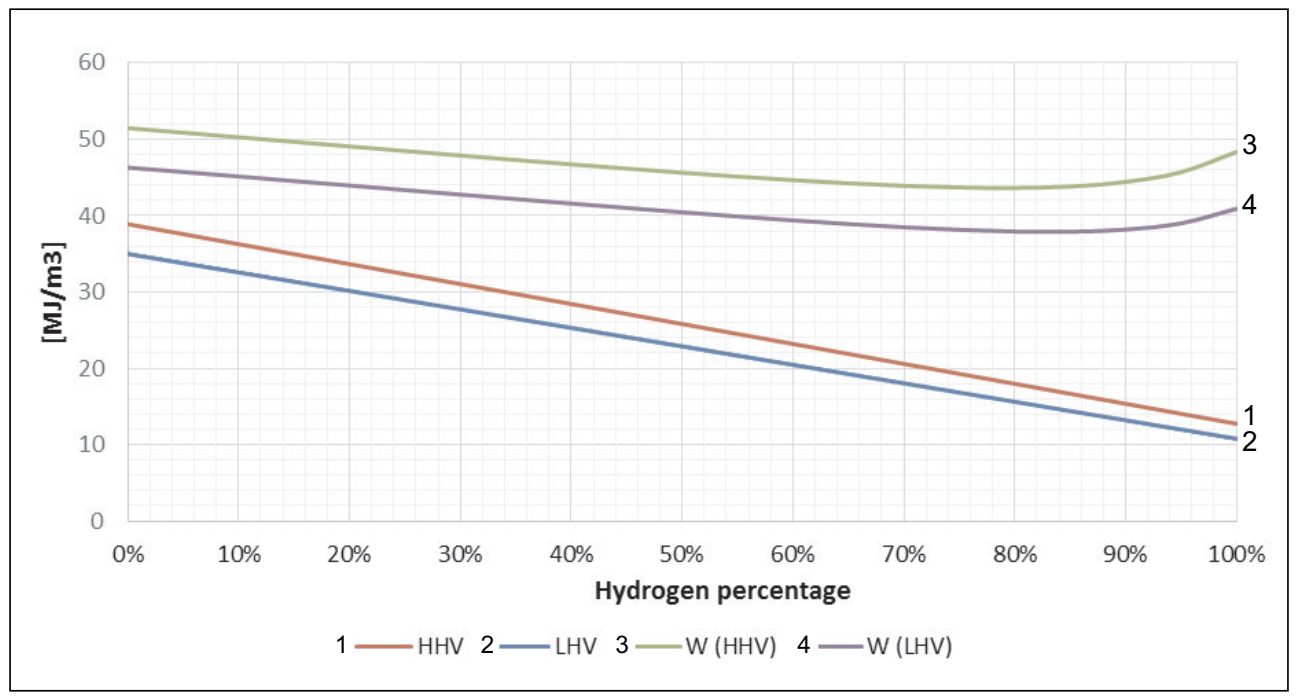

Fig. 5. Lower Heating Value (LHV) $\left[\mathrm{MJ} / \mathrm{m}^{3}\right]$, Higher Heating Value (HHV) $\left[\mathrm{MJ} / \mathrm{m}^{3}\right]$, lower Wobbe index $\left[\mathrm{MJ} / \mathrm{m}^{3}\right]$ and upper Wobbe index $\left[\mathrm{MJ} / \mathrm{m}^{3}\right]$ vs. percentage of hydrogen in natural gas being transported

Lower heating value and higher heating value of the gas being transported decrease according to the amount of hydrogen added. This drop can be seen in Table 1 .

Table 1

Decrease in higher heating value (HHV) and lower heating value (LHV) vs. amount of hydrogen added vs. natural gas without hydrogen blend content

\begin{tabular}{|c|c|c|}
\hline Hydrogen percentage [\%] & HHV decrease [\%] & LHV decrease [\%] \\
\hline 0.00 & 0.00 & 0.00 \\
\hline 5.00 & 3.36 & 3.46 \\
\hline 10.00 & 6.72 & 6.92 \\
\hline 15.00 & 10.08 & 10.37 \\
\hline 20.00 & 13.44 & 13.83 \\
\hline 30.00 & 20.16 & 20.75 \\
\hline
\end{tabular}

After August 1, 2014 all energy companies in Poland are legally required to settle the accounts with customers in units of energy, and for that reason the amount of energy that can happen under actual conditions within a cubic metre of the transmitting mixture has been computed. The results are shown in Figure 6 . 


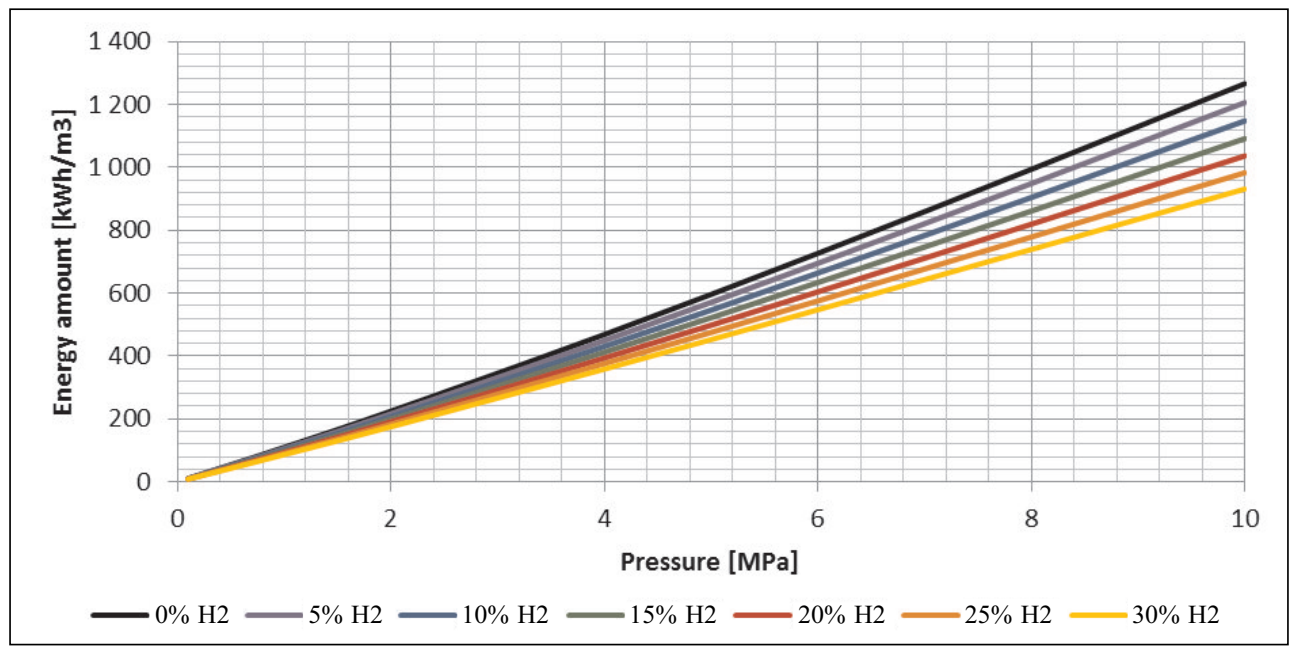

Fig. 6. Amount of energy $[\mathrm{kWh}]$ transmitted within $1 \mathrm{~m}^{3}$ of gas $v s$. pressure and hydrogen percentage in natural gas

\section{HYDROGEN AND NATURAL GAS BLEND TRANSPORTED BY PIPELINES}

As a fuel, natural gas is transported by gas pipelines. A key element of considerations regarding its transmission is the question of pressure drop over a given distance at the point of entry. This loss in pressure is non-linear and provides the basis for planning to place a gas compression station within transmission network in order to compress the gas and increase its pressure. Without pressure being increased it would not be possible to transmit gas over longer distances. The pressure is reduced due to pipeline characteristics and hydrodynamic parameters of the fluid being transmitted.

As in the case of previously examined gas parameters, the mixtures containing from $0 \%$ to $30 \%$ hydrogen have been considered. The principles for determining the composition and the starting composition (natural gas without hydrogen blend content) are the same as previously analysed. In order to calculate the pressure drop that will occur at a given transmission distance, the following Panhandle B equation (4) for turbulent gas flow in porous pipelines was used [3]:

$$
\begin{gathered}
Q_{n}=108.080 \frac{1}{\mu^{0.02}} \frac{T_{n}}{P_{n}}\left[\frac{\left(P_{1}^{2}-P_{2}^{2}\right)-E}{L d^{0.9608} T_{a v g} Z_{a v g}}\right]^{0.51} D^{2.53} \\
E=0.06843 d\left(H_{2}-H_{1}\right) \frac{P_{a v g}^{2}}{T_{a v g} Z_{a v g}}
\end{gathered}
$$


where:

$E$ - expression for potential energy $\left[\mathrm{Pa}^{2}\right]$,

$Q_{n}$ - volumetric flow rate under normal conditions $\left[\mathrm{m}^{3} / \mathrm{s}\right]$,

$\mu$ - dynamic viscosity of gas $[\mathrm{Pa} \cdot \mathrm{s}]$,

$T_{n}$ - normal temperature $[\mathrm{K}]$,

$P_{n}-$ normal pressure [Pa],

$P_{1}-$ gas pressure at the upstream end of the measured section [Pa],

$P_{2}$ - gas pressure at the downstream end of the measured section [Pa],

$L$ - pipe length (or measured section length) [m],

$d$ - gas relative density, dimensionless,

$T_{\text {avg }}$ - average gas temperature $[\mathrm{K}]$,

$Z_{\text {avg }}$ - gas pseudo-compressibility factor, dimensionless,

$D$ - gas pipe inside diameter [m],

$H_{1,2}$ - gas pipe height at the upstream end (1) and the downstream end (2) of the measured section [m],

$P_{a v g}$ - average gas pressure $[\mathrm{Pa}]$.

In the interest of simplification a fixed gas pipe height has been assumed, and thus, the potential energy of gas transmitted by such a pipeline is $0 \mathrm{~Pa}^{2}$. The normal pressure is $101.325 \mathrm{kPA}$, the normal temperature is $273.15 \mathrm{~K}$, the relative density of gas is the normal density of a given gas (for the analysed blend without hydrogen it is $0.738 \mathrm{~kg} / \mathrm{m}^{3}$ ) divided by the normal density of air $\left(1.293 \mathrm{~kg} / \mathrm{m}^{3}\right)$. The dynamic viscosity of gas is usually given as a constant, due to its small variations depending on pressure and temperature (the authors of the study [3] state that the typical constant is $1.0758 \cdot 10^{-5} \mathrm{~Pa} \cdot \mathrm{s}$ ). It was decided, though, to take account of its variations, by computing its value through Lee-Gonzalez correlation [9]. The pipeline to be considered was the $150 \mathrm{~km}$ gas pipeline with a diameter of $1000 \mathrm{~mm}$ and a nominal flow of $3.3 \mathrm{mln} \mathrm{m} / \mathrm{h}$. In order to adequately analyse the pressure variations over the whole length, the pipeline was divided into $5 \mathrm{~km}$ sections where variations of all pressure parameters were examined in order to eventually obtain the pressure value at the downstream end of the investigated section. The initial pressure (i.e. at $0 \mathrm{~km}$ distance) was assumed at $10 \mathrm{MPa}$. For computation purposes, the average temperature in the pipeline was assumed equal to $7^{\circ} \mathrm{C}$. Gas pressure at the downstream end of the measured section was computed after rearranging the equation (4) - the graphs illustrating pressure variations at the distances between the $100^{\text {th }}$ and the $150^{\text {th }} \mathrm{km}$ are shown below (pressure variation over shorter distances is modest). As the pressure decreases, the gas velocity increases. Figures 7 and 8 demonstrate these variations.

Figure 7 shows that the greater the percentage of hydrogen transported with natural gas, the smaller the pressure drop over a given distance. It is mainly due to the lower relative density of the gas and the higher pseudo-compressibility $Z$ factor for blends with higher percentage of hydrogen and because of their lower viscosity (equ (4)). In this context, it is important to note the fact that the applied equation has been obtained empirically, as it is true for other equations describing the transport of natural gas. Since there are no similar equations for hydrogen and natural gas blends, it should not be forgotten that the nature of such a mixture flow may differ from that previously assumed in the equations for natural gas. 


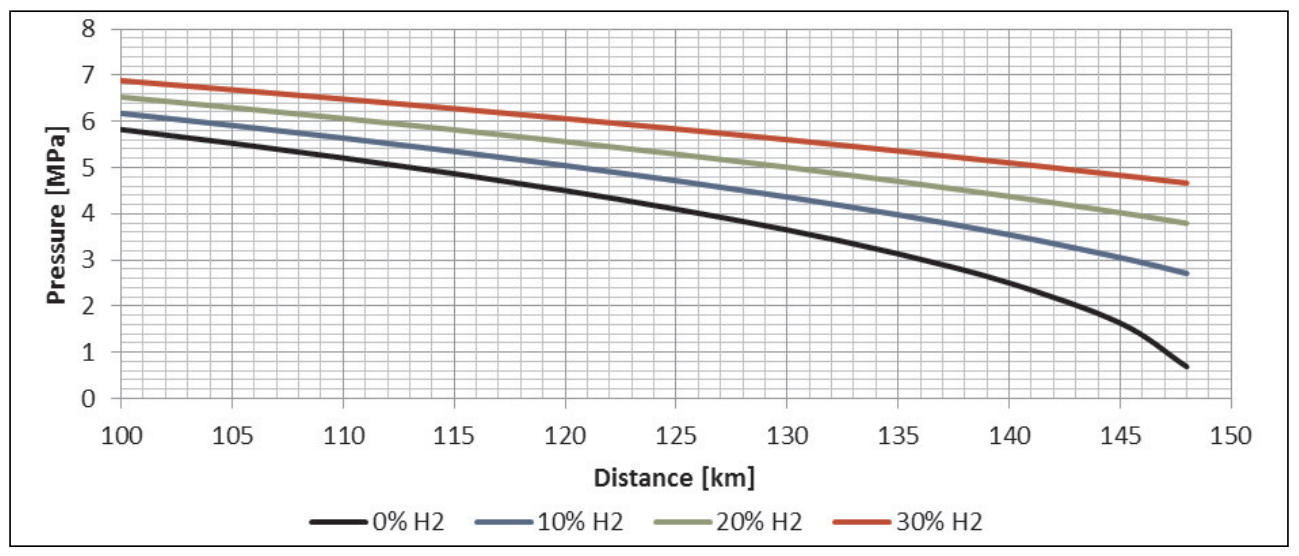

Fig. 7. Variation in natural gas pression transmitted over a given distance vs. percentage of hydrogen in the blend

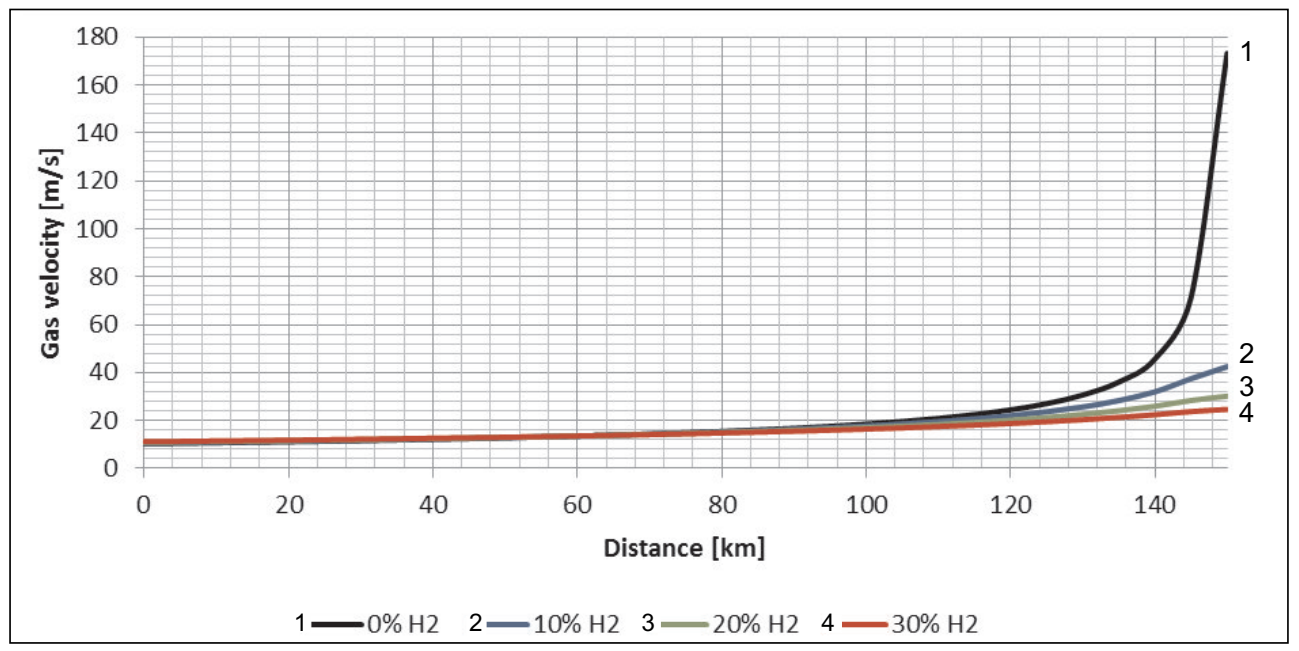

Fig. 8. Variation in gas velocity in a gas pipeline over a given distance $v s$. percentage of hydrogen in the blend

According to calculations being made, the pressure drop in the final three kilometres is lower by $82 \%$ in the blend with $30 \%$ hydrogen, unlike in the case of pure natural gas. It has also been calculated that while the mixture without hydrogen reaches the pressure close to atmospheric pressure between the $148^{\text {th }}$ and the $149^{\text {th }}$ kilometre of the gas pipeline, the mixture with $10 \%$ hydrogen behaves similarly close to the $160^{\text {th }}$ kilometre, with $20 \%$ hydrogen - before the $172^{\text {nd }}$ kilometre, and with $30 \%$ hydrogen only before the $188^{\text {th }}$ kilometre. Therefore, hypothetically, the last blend may be transmitted about 40 kilometres further (which at the $148^{\text {th }}$ kilometre for pure natural gas is a $27 \%$ greater value).

With a view to increasing the use of hydrogen, there have been considerations to transport hydrogen blended with natural gas by means of the available gas network. 
Therefore, the amount of energy, the so-called linepack, that would be present in a gas pipeline with different diameters and transmission capacities was calculated according to the percentage of hydrogen added. Diameters DN300, DN500, DN700, DN900 and DN1000 were considered, while the transmission capacity was sized to be suitable for gas pressure at $2 \mathrm{MPa}$ at the distance of $110 \mathrm{~km}$, using the previously shown formula for gas flow in pipelines (4) and the assumptions under which the pressure drop was calculated. Table 2 shows capacity values for given diameters, while Figures 9-13 provide the amount of energy accumulated in a gas pipeline with stated parameters.

Table 2

Assumed diameters and transmission capacities to compute accumulated energy levels

\begin{tabular}{|c|c|}
\hline $\begin{array}{c}\text { Diameter } \\
{[\mathrm{mm}]}\end{array}$ & $\begin{array}{c}\text { Transmission capacity } \\
{[\mathrm{mcm} / \mathrm{h}]}\end{array}$ \\
\hline 300 & 180 \\
\hline 500 & 654 \\
\hline 700 & 1531 \\
\hline 900 & 2892 \\
\hline 1000 & 3776 \\
\hline
\end{tabular}

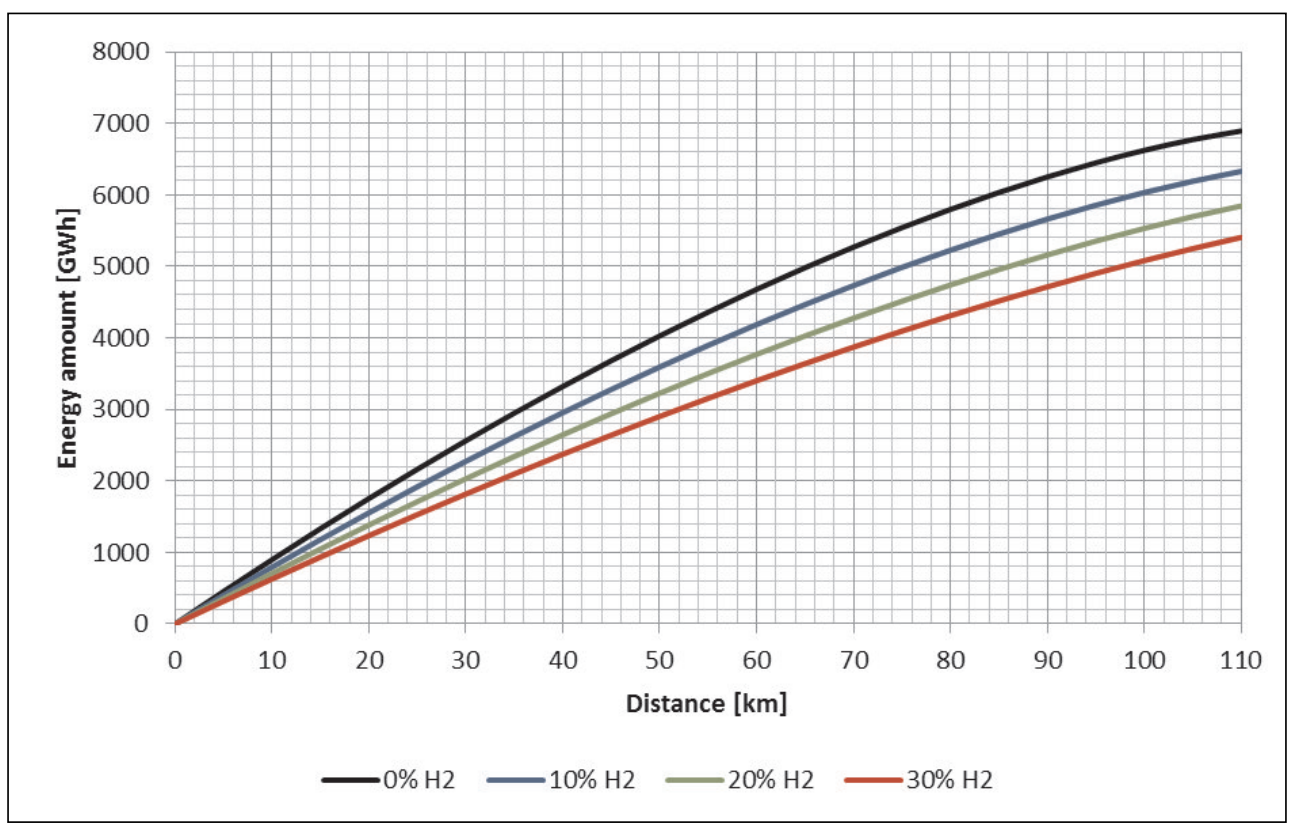

Fig. 9. Amount of energy accumulated in a pipeline with a diameter of $300 \mathrm{~mm} v s$. percentage of hydrogen in the blend and the distance 


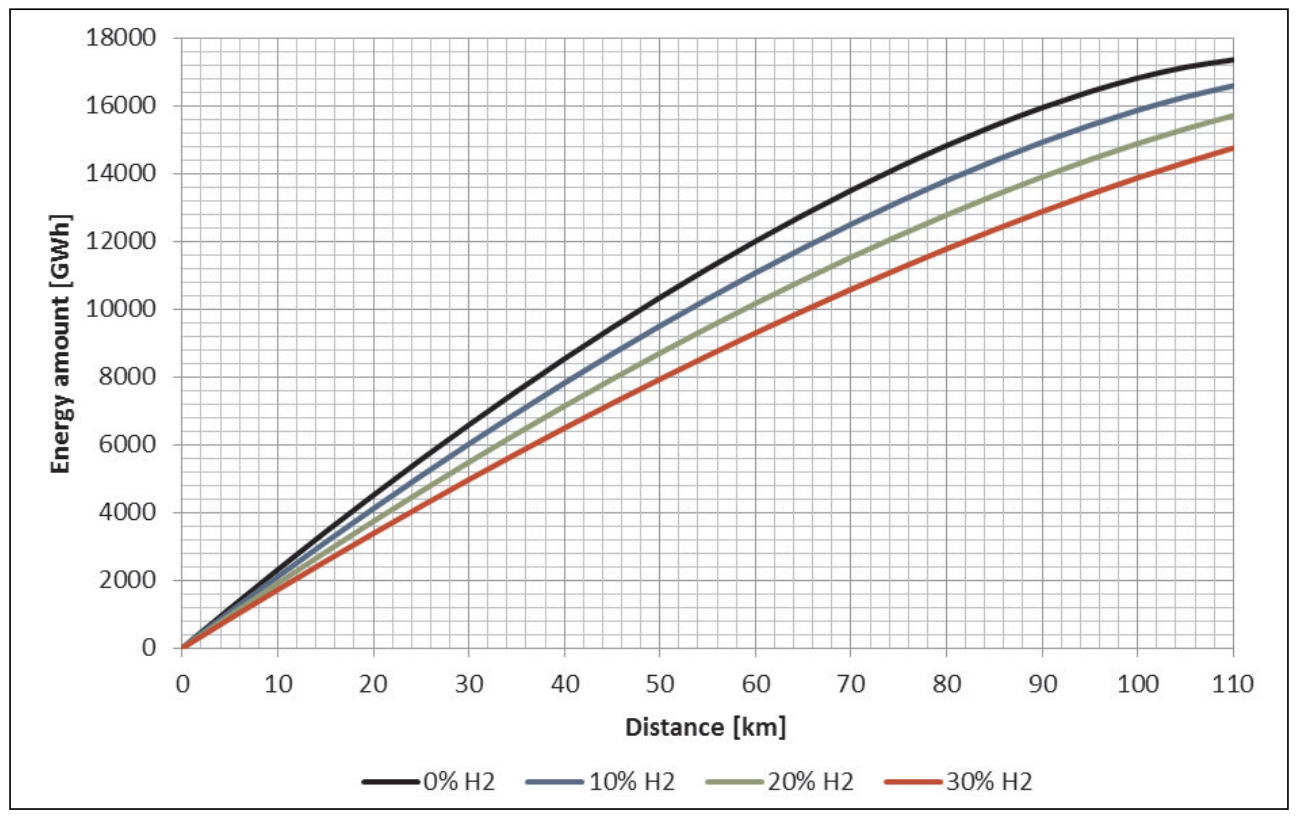

Fig. 10. Amount of energy accumulated in a pipeline with a diameter of $500 \mathrm{~mm} v s$. percentage of hydrogen in the blend and the distance

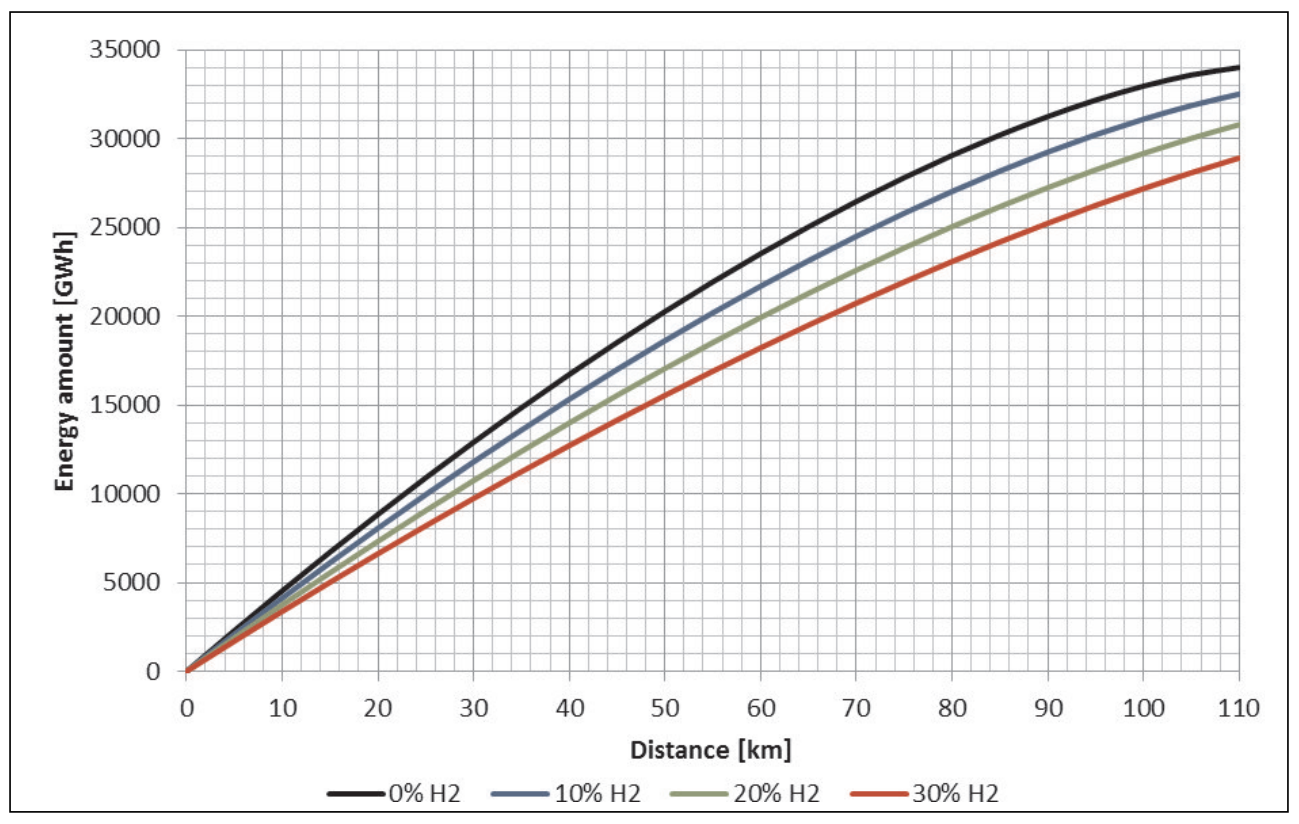

Fig. 11. Amount of energy accumulated in a pipeline with a diameter of $700 \mathrm{~mm} v s$. percentage of hydrogen in the blend and the distance 


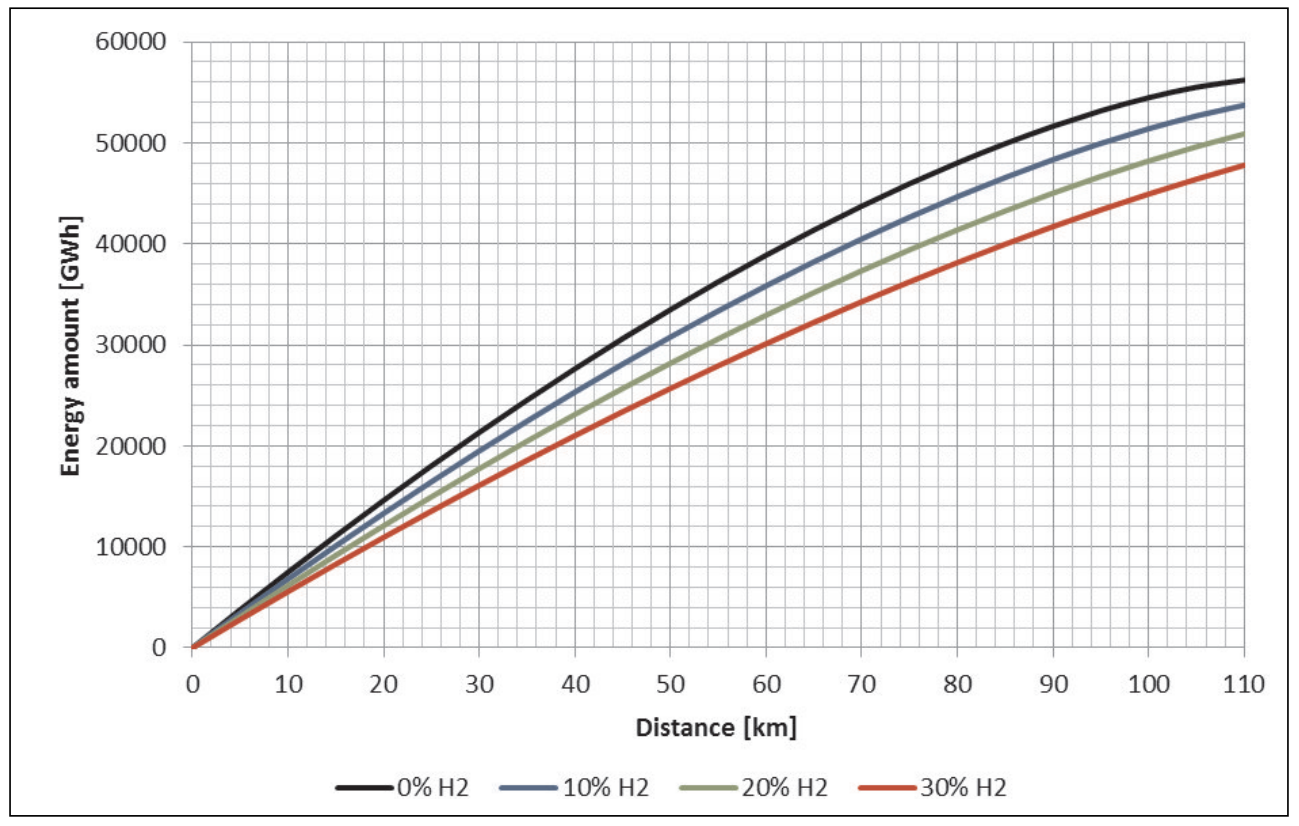

Fig. 12. Amount of energy accumulated in a pipeline with a diameter of $900 \mathrm{~mm} v s$. percentage of hydrogen in the blend and the distance

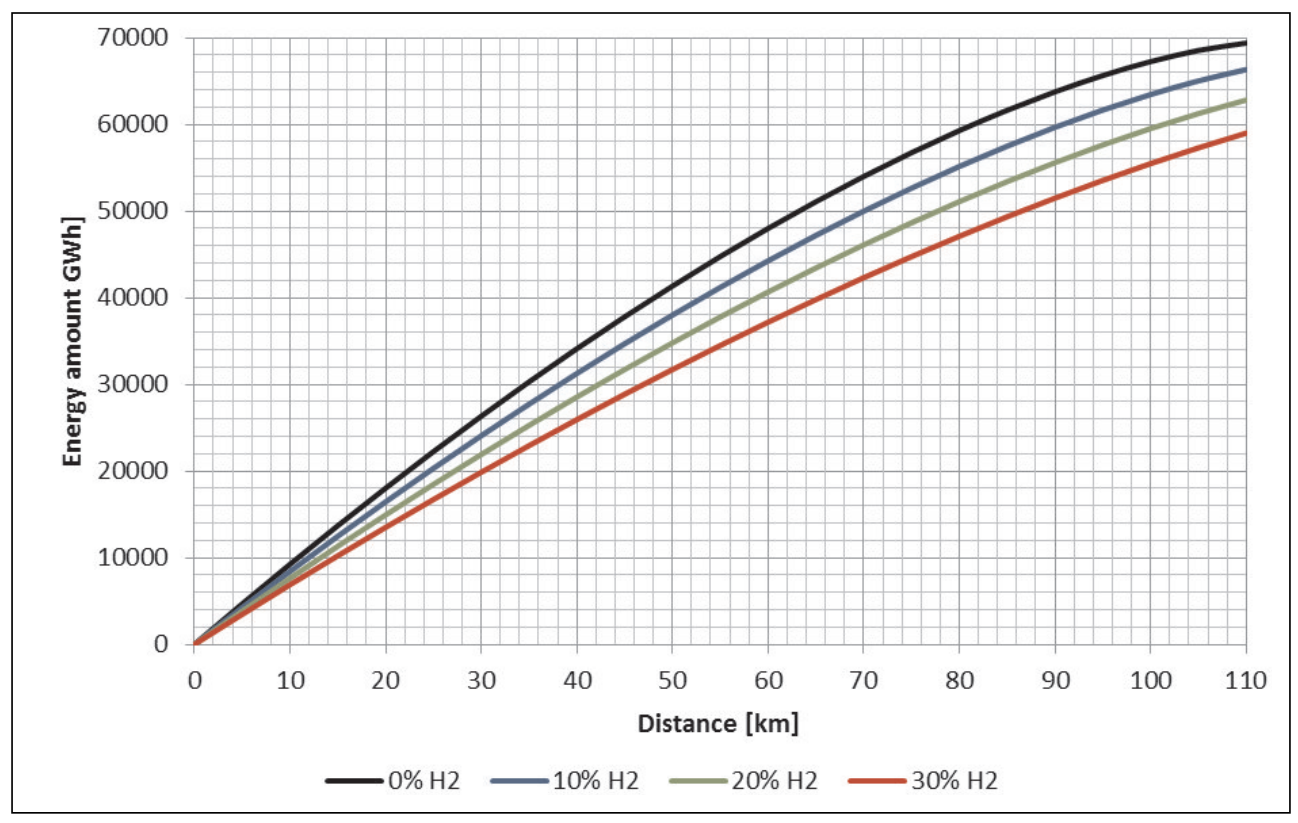

Fig. 13. Amount of energy accumulated in a pipeline with a diameter of $1000 \mathrm{~mm} v s$. percentage of hydrogen in the blend and the distance 


\section{CONCLUSIONS}

Hydrogen is a gas that differs substantially from basic components of natural gas. Therefore, blending it with natural gas transported through gas pipeline networks will have significant implications on the parameters of such a blend. Since 1975, the nature of these changes and the actual possibility to implement similar projects have been addressed by a number of authors [15].

It should be noted that transmitting hydrogen blend with natural gas remains an open issue and requires sufficient attention. At the moment there are no tried and tested algorithms on which to rely while forecasting the parameters for the mixture of natural gas and hydrogen under transmission conditions.

On the basis of calculations performed one may conclude that blending hydrogen with natural gas will significantly decrease the heating value of the transmitted blend, which is one of the main parameters showing the quality of fuels being transmitted. It should not be forgotten, though, that the energy contained in hydrogen has been obtained through the conversion of excess electricity generated from renewable energy sources; if the conversion had not taken place, the energy would have been wasted. Thus, although the energy value of natural gas is reduced by hydrogen blending, in terms of economics of using actually generated energy the incurred losses would be smaller. It is also important to remember that settlements with end-consumers are made in units of energy, and therefore, it will not damage the quality of the services rendered; however, financial benefits of an energy company providing transmission services will be lower.

A significant consideration of the subject is the safe hydrogen use. Respectfully, a comparison was made of petrol, methane and hydrogen in the work [7]. While hydrogen has a very low minimum ignition energy and a wide explosive range in the mixture with air, during its combustion no organic products are present, as it is true for natural gas constituents. This, again, results in no evidence of toxicity. Due to its low density and high capability to diffuse, when leaking, hydrogen goes up in the vertical direction, faster than any other natural gas constituent, creating an explosion-risk area with a shorter radius. The mixture of natural gas and hydrogen will therefore have a wider explosive range and will need lower energy to ignite but the formation of explosive atmosphere will be curtailed. In the event of flaws in gas combustion system, which leads to the production of carbon monoxide as a result of the oxidation of organic components, its quantities will also be lower due to reduced percentage of these constituents.

Another important aspect in addressing the question of natural gas transport through transmission network is the pressure drop within the gas pipeline. The blend of natural gas with hydrogen, due to physical characteristics of the latter, is characterised by much smaller pressure drops, which enables the blend to be transmitted over longer distances.

It results from the above that blending hydrogen with natural gas has major implications on transmission parameters of the mixture transported through a gas pipeline network, which justifies and requires further analysis and investigation on the subject. 


\section{REFERENCES}

[1] Bartknecht W.: Explosions. Springer-Verlag, Berlin Heidelberg New York 1981.

[2] Chemical Safety Sheets. Chemical Industry Association, Netherlands. Springer 1991.

[3] Coelho P.M., Pinho C.: Considerations About Equations for Steady State Glow in Natural Gas Pipelines. Journal of the Brazilian Society of Mechanical Sciences and Engineering, vol. 29, no. 3, 2007.

[4] Dodds P.E., Demoullin S.: Conversion of the UK gas system to transport hydrogen. International Journal of Hydrogen Energy, vol. 38, Issue 18, 2013, pp. 7189-7200.

[5] Gaz-System S.A. www.gaz-system.pl (access: 5.03.2016).

[6] Glor M., Thurnherr P.: Ignition Hazards Caused by Electrostatic Charges in Industrial Processes. Thuba Ltd. 2015

[7] Gupta R.B., Basile A., Veziroglu T.N. (Eds).: Compendium of Hydrogen Energy. Vol. 2: Hydrogen Storage, Distribution and Infrastucture. Elsevier 2015.

[8] Haeseldonckx D., D'haeseleer W.: The use of the natural gas pipeline infrastructure for hydrogen transport in a changing market structure. International Journal of Hydrogen Energy, vol. 32, Issues 10-11, 2007, pp. 1381-1386.

[9] Lee A.L., Gonzalez M.H., Eakin B.E.: The Viscosity of Natural Gases. Journal of Petroleum Technology, vol. 18(08), 1966.

[10] Nagy S. (Ed.).: Vademecum gazownika. Vol. I. Stowarzyszenie Naukowo-Techniczne Inżynierów i Techników Przemysłu Naftowego i Gazowniczego SITPNiG, Kraków 2014.

[11] Melaina M.W., Antonia O., Penev M.: Blending Hydrogen into Natural Gas Pipeline Networks: A Review of Key Issues. National Renewable Energy Laboratory, March 2013. http://www. nrel.gov/docs/fy13osti/51995.pdf (access 01.03.2016).

[12] PN-M-34034:1976- wersja polska. Rurociąi - Zasady obliczeń strat ciśnienia.

[13] Tong M.-M., Wu G.-Q., Hao J.-F., Dai X.-L.:. Explosion limits for combustible gases. Mining Science and Technology (China), 19, 2009, pp. 182-184.

[14] Veziroğlu T. Nejat: Hydrogen Energy. 1975. http://link.springer.com/book/10.1007/ 978-1-4684-2607-6. 